\title{
Attempts to calculate the pseudo-anisotropy of elastic parameters of shales gas formations based on well logging data and their geostatistical analysis
}

\author{
Maria Bała, Adam Cichy, Monika Wasilewska-Błaszczyk \\ AGH University of Science and Technology, Department of Geology, Geophysics and Environmental Protection; \\ al.A. Mickiewicza 30,30-059Krakow,Poland;e-mail:bala@geol.agh.edu.pl, cichy@agh.edu.pl, monika.wasilewska@agh.edu.pl
}

(C) 2019 Authors. This is an open access publication, which can be used, distributed and reproduced in any medium according to the Creative Commons CC-BY 4.0 License requiring that the original work has been properly cited.

Received: 16 October 2018; accepted: 07 January 2019; first published online: 15 February 2019

\begin{abstract}
This paper presents the attempts to calculate the pseudo-anisotropy of elastic parameters for the Silurian and Ordovician shale formations of several wells located in the Baltic basin. For this purpose, well-logging data were used, in particular data recorded with acoustic dipole tools. With the $\mathrm{P}$ and $\mathrm{S}$ waves velocities available, measured at the dipole setting in two orthogonal directions XX or YY $\left(\mathrm{S}_{\text {Fast }}\right.$ and $\left.\mathrm{S}_{\text {Slow }}\right)$, the elastic $\varepsilon$ and $\gamma$ parameters were calculated. In this paper we evaluate the effect of different factors e.g., porosity, clay and kerogen content on the velocity of anisotropy shale gas formations. A geostatistical analysis of elastic and reservoir properties was carried out in order to determine the character of the variability of Silurian and Ordovician shale formations in all of the studied wells. Semivariograms for each well characterizing the variation of elastic parameters in the vertical direction were calculated.
\end{abstract}

Keywords: anisotropy parameters, $\mathrm{P}$ and $\mathrm{S}$ velocities, Baltic Basin, shale gas formation, acoustic dipole tool, semivariogram

\section{INTRODUCTION}

The problem of rock anisotropy and its effect on recorded velocities in acoustic profiling in boreholes has been investigated for many years, with a wide range of laboratory tests having been conducted to consider this issue.

The most important publications in this field are the works of Tosaya (1982), Han et al. (1986), Eastwood \& Castagna (1983), Castagna et al. (1985), Marion et al. (1992), Vernik \& Nur (1992), Hornby et al. (1994), Johnston \& Christensen (1995), Wang et al. (2001), and Sondergeld \& Rai (2011). They studied the influence of various factors on the shale elastic parameters under different pressure conditions. The elastic properties of individual clay minerals are important for understanding wave propagation through shales. Mondol et al. (2008) and Sato et al. (2005) estimate the elastic moduli of smectite and kaolinite using ultrasonic measurements and extrapolating the measured variation in elastic moduli with different porosity. Significant differences in elastic properties under dry and brine-saturated conditions are observed. In the work of Prasad et al. (2002) the results of measurements of Young's modulus of clay minerals using atomic force acoustic microscopy were presented. Similarly, the mechanical properties of shale gas reservoir rocks were studied in the works of Bayuk et al. (2007), Wenk et al. (2008), and Sone \& Zoback (2013). 
Vanorio et al. (2008), Sayers (2005, 2013), and Allan et al. (2015) investigated the effect of kerogen on the elastic anisotropy of organic-rich shales. Shale anisotropy were also studied by Zalewska et al. (2009), Bandyopadhyay (2009), Carcione et al. (2011), Horne, et al. (2012), Zhao et al. (2016), Zhang et al. (2017) and many others. Recently, the authors of this publication also dealt with the problem of rock anisotropy based on data from the acoustic methods or electrical measurements in wells (Bała 2011, Bała \& Cichy 2015). A separate problem is the evaluation of anisotropy based on seismic surveys which are not discussed in this article.

Clastic rocks anisotropy has a significant effect on longitudinal and shear wave velocities that are measured in acoustic logging. A series of anisotropic rocks can be formed as a result of deposition and tectonic stress. Anisotropy can be regarded in the macroscopic scale (the lamination of rock formations), and in the microscopic scale (e.g., reservoir rocks with fractional arrangement of grains of different sizes). Likewise, the anisotropy of rocks caused by fractures or microfissures is also observed in rocks (Bała 2009, 2011).

The most well-known are described by Thom$\operatorname{sen}(1989)$ anisotropy parameters $\varepsilon, \gamma, \delta$ characteristic for the transverse isotropic media with a vertical symmetric axis (VTI).

An interesting method to assess the parameters of anisotropy in sandstone and clay rocks was presented by Li $(2004,2006)$.

\section{ANISOTROPY PARAMETERS}

Theoretical modeling of the response of acoustic tools in sandstone and clay rocks usually assumes simplified models of anisotropic media (for example: Thomsen 1986, Vernik \& Nur 1992, Carcione et al. 2011).

In the simplest case of anisotropy with hexagonal symmetry (VTI - Vertical Transverse Isotropy with a vertical axis of symmetry) the stiffness tensor matrix has five independent coefficients out of 12 non-zero (Thomsen 1986): $c_{11}, c_{33}, c_{44}, c_{66}$ and $c_{13}$.

Velocities propagating along and perpendicular to the axis of symmetry, and at angles in between, depend on these five components and the bulk density. Taking the $x 3$-axis to lie along the axis of rotational symmetry, the non-vanishing elastic stiffness coefficients are: $c_{11}=c_{22}, c_{33}, c_{12}=c_{21}$, $c_{13}=c_{31}=c_{23}=c_{32}, c_{44}=c_{55}$ and $c_{66}=\left(c_{11}-c_{12}\right) / 2$ (the conventional two-index notation). Since an isotropic medium can be described by two elastic constants, a transversely isotropic medium has three anisotropy parameters (Sayers 2005).

Thomsen (1986) introduces three elasticity parameters: $\varepsilon, \gamma$ and $\delta$, defining them as a combination of $c_{\alpha \beta}$ elastic moduli to characterize the VTI transverse isotropic medium.

$\varepsilon=\frac{c_{11}-c_{33}}{2 \cdot c_{33}}, \quad \gamma=\frac{c_{66}-c_{44}}{2 \cdot c_{44}}$

$\delta=\frac{\left(c_{13}+c_{44}\right)^{2}-\left(c_{33}-c_{44}\right)^{2}}{2 \cdot c_{33} \cdot\left(c_{33}-c_{44}\right)}$

These parameters determine the shape of the $\mathrm{P}$ and $S$ waves fronts in the VTI medium.

The $\varepsilon$ parameter is characterized by the difference between the vertical and horizontal velocity of the propagating wave $\mathrm{P}, \gamma$ the difference between the velocity of the $S$ wave propagating horizontally and vertically (polarized vertically SV or polarized horizontally SH) (Mavko et al. 2009). These parameters are usually determined as $\mathrm{P}$ and $\mathrm{S}$ waves anisotropy parameters. Banik (1987) states that of these three parameters, $\delta$ has the greatest effect on the amplitude of the reflected wave $\mathrm{P}$, with a small distance between the source and receiver points and in the case of weak anisotropy.

In publications (Thomsen 1986, Ryan-Grigor 1997) tables are presented, taken from many other publications, in which the parameters of anisotropy measured on samples from various rocks were studied: sandstones, limestones, shales, clays, calcite crystals, biotite, apatite and others, under various measurement conditions (dry, air-dry) at given pressures.

The tables contain values: $V_{\mathrm{P}}, V_{\mathrm{S}}, V_{\mathrm{P}} / V_{\mathrm{S}}, \varepsilon, \gamma$ and $\delta$ as well as the density of the individual samples. The analysis of these parameters shows that $\varepsilon, \gamma$ and $\delta$ can take positive and negative values. It has also been observed that $\delta$ correlates well with the ratio of $\mathrm{P}$ wave velocity propagating vertically and $\mathrm{S}$ wave velocity propagating along the vertical axis. 


\section{INFLUENCE OF CLAYING ON $V_{\mathrm{P}}, V_{\mathrm{S}} V$ ELOCITIES AND THE RATIO $V_{\mathrm{p}} / V_{\mathrm{S}}$}

The elastic properties of shales depend on their composition, the volume of individual fractions, shapes and the orientation of grains. In the work of Zhu et al. (2001) it was stated that $V_{\mathrm{p}} / V_{\mathrm{S}}$ is linear from 1.6 in the absence of clay up to 2.1 for a high content of clay fraction.

The author introduces the concept of "critical clay content" (about $40 \%$ ), below which the elastic parameters behave in accordance with theoretical calculations for a mixture of sandstone and clay. Above this critical clay content, there is a decrease in $V_{\mathrm{p}}$ and $V_{\mathrm{S}}$ with an increase in clay fraction. Similar observations as to the critical volume of clays are presented on the basis of laboratory tests (Marion et al. 1992), which have not been confirmed in other publications (e.g., Castagna et al. 1993, Han et al. 1986). The calculations made by (Bała 2007) using the theoretical models of Kuster-Toksöz and Biot-Gassmann show a strong influence of clay material on the $\mathrm{P}$ and $\mathrm{S}$ waves velocities as well as the elastic moduli and Poisson's coefficient, but also the critical volume of clays is not observed.

The $V_{\mathrm{P}} / V_{\mathrm{S}}$ ratio for different clay minerals can vary considerably due to the anisotropy observed in them (Katahara 1996). For waves propagating along the XY plane perpendicular to the well direction, the longitudinal wave velocity $V_{\mathrm{Psh}}$ in clay rocks is expressed with the $c_{11}$ elastic constant and shale density $\rho_{\text {sh }}$, the shear wave velocity polarized in the layering direction $V_{\mathrm{SH} s h}$ contains the elastic constant $c_{66}$, and the transverse polarized wave velocity $V_{\mathrm{SVsh}}$ perpendicular to the layering component $c_{44}$ :

$V_{\mathrm{Psh}}=\sqrt{\frac{c_{11}}{\rho_{\mathrm{sh}}}}, V_{\mathrm{SHsh}}=\sqrt{\frac{c_{66}}{\rho_{\mathrm{sh}}}}, V_{\mathrm{SVsh}}=\sqrt{\frac{c_{44}}{\rho_{\mathrm{sh}}}}$

In Sayers' paper (2005), the Thomsen anisotropy parameters $\varepsilon, \gamma$ and $\delta$ calculated for the clay minerals on the basis of the measured components $c_{11}, c_{33}, c_{44}, c_{66}$ and $c_{13}$ are presented in the form of tables. It was noted that the $\varepsilon$ and $\gamma$ values are positive, while the $\delta$ values are negative or have low positive values.
Li (2006) presents the method of calculating the anisotropy parameters $\varepsilon$ and $\gamma$ based on recorded velocities $V_{\mathrm{P}(0)}, V_{\mathrm{s}_{(0)}}$ and clay volume, using laboratory data published by Thomsen (1986), Vernik \& Nur (1992), Johnston \& Christensen (1995) and Vernik \& Liu (1997).

Using the crossplot based on this data (Fig. 1) the $\varepsilon$ parameter is defined as:

$$
\varepsilon=\frac{\varepsilon_{\mathrm{cl}} \cdot V_{\text {clay }} \cdot\left(V_{\mathrm{P}(0)}-V_{\mathrm{P} \text { water }}\right)}{V_{\mathrm{P} \text { quartz }}-V_{\mathrm{P} \text { water }}-a \cdot V_{\text {clay }}}
$$

Similarly, the parameter $\gamma$ is defined as:

$\gamma=\frac{\gamma_{\mathrm{cl}} \cdot V_{\text {clay }} \cdot V_{\mathrm{S}(0)}}{V_{\mathrm{Squartz}}-b \cdot V_{\text {clay }}}$

where:

$V_{\text {clay }}$ - volume of clay,

$V_{\mathrm{P}(0)}\left(\right.$ or $\left.V_{\mathrm{P}}\right)$ - P-wave velocity perpendicular to bedding,

$V_{\mathrm{P}_{\text {water }}}$ - an approximation of P-wave velocity at critical porosity,

$V_{\text {Pquartz }}$ - P-wave velocity of quartz (Fig. 1),

$V_{\mathrm{S}(0)}\left(\right.$ or $\left.V_{\mathrm{S}}\right)-\mathrm{S}$-wave velocity perpendicular to bedding,

$V_{\text {Squartz }}$ - S-wave velocity of quartz,

$\varepsilon_{\text {clay }}=0.70$ and $\gamma_{\text {clay }}=0.72$ (vide Li 2004).

On the graph of $V_{\mathrm{P}(0)}$ versus the anisotropy parameter $\varepsilon, \mathrm{Li}$ (2004) marks three main points corresponding to: 1) "critical porosity sand point", 2) "mineral sand point (or quartz point)", and 3) "clay mineral point" (Fig. 1). Similarly, he works with the graph for the $\gamma$ parameter.

The critical porosity sand point (for porosity $\Phi=40 \%)$ has a zero effective shear modulus and zero shear velocity which indicates that the rock is in the suspension domain. The effective compressional velocity of clastic rocks at this point may be approximated by the velocity of brine. The properties of quartz are used as an approximation of sand with zero porosity. Notice that both the critical porosity sand point and zero porosity sand point are associated with zero anisotropy. Finally, the clay mineral point is determined using the mean of the data points with the largest anisotropic values. 


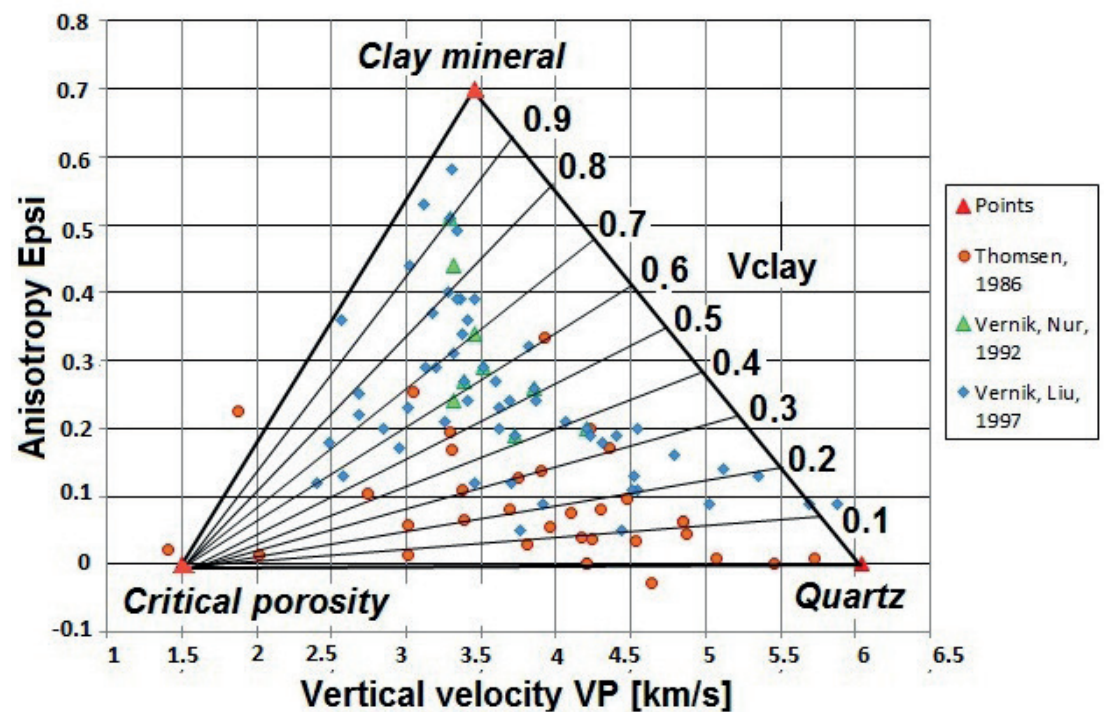

Fig. 1. The relationship between anisotropic parameters $\varepsilon$ and the $P$-wave velocities perpendicular to bedding $\left(V_{p}\right)$, and clay volume $V_{\text {clay }}$ (Li 2004) (modified by authors)

The coefficients $a$ and $b$ in equations (3) and (4) can be defined as follows. The slope for any line was determined (Li 2006):

$m=\frac{y_{1}-y_{0}}{x_{1}-x_{0}}$

Thus:

$y_{1}-y_{0}=\varepsilon_{\text {clay }} \cdot V_{\text {clay }}$

and

$x_{1}-x_{0}=V_{\text {Pwater }}-\left(V_{\text {Pquartz }}-V_{\text {Pclay }}\right) \cdot V_{\text {clay }}$

and similarly, the coefficient $b$ can be determined.

In the (2004) publication, Li adopted the following values in equations (3) and (4): $V_{\text {Pwater }}=$ $=1.5 \mathrm{~km} / \mathrm{s}, V_{\text {Pquartz }}=6.05 \mathrm{~km} / \mathrm{s}, V_{\text {Squartz }}=4.09 \mathrm{~km} / \mathrm{s}$, $V_{\text {Pclay }}=3.4 \mathrm{~km} / \mathrm{s}, V_{\text {Sclay }}=1.8 \mathrm{~km} / \mathrm{s}, \varepsilon_{\text {clay }}=0.7$, and $\gamma_{\text {clay }}=0.72$, for the clay point (derived are especially useful because they are rarely determined in laboratory data).

\section{CALCULATING}

\section{THE ELASTIC PARAMETERS OF SHALE GAS FORMATIONS}

This method was applied to the Silurian and Ordovician shale formations in wells K1, O2, L1, B1 and W1 drilled in the Baltic Basin (Fig. 2).
These wells were drilled vertically, and the drilled structures lie almost horizontally $\left(0-5^{\circ}\right)$.

Therefore, one can assume that the medium is vertically transverse in isotropic (VTI).

Prior to the calculation, available laboratory data were analyzed for the mineral composition of the Silurian and Ordovician formations (wells documentations).

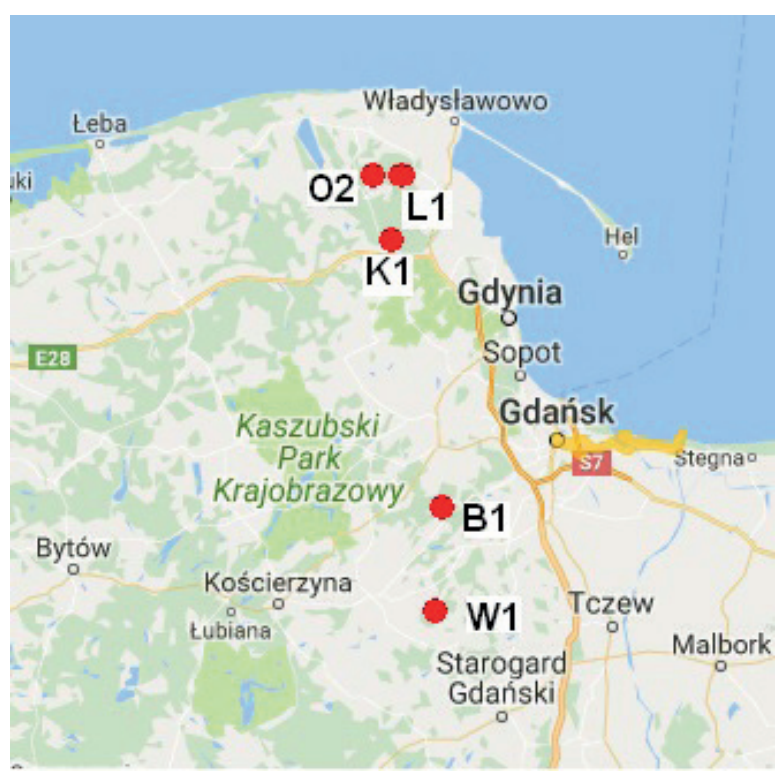

Fig. 2. The approximate location of the investigated boreholes (www.mapa-polski.org/kujawsko-pomorskie,rw.html, access: June 2018) 
The predominant minerals in the tested wells in the samples taken from the Silurian deposits are minerals, mainly illites (usually $>55 \%$ ) and quartz (an average of 20\%). The samples also contain plagioclases, potassium feldspar and iron sulphides. The velocity parameters can be determined by measuring with the Compact Cross Dipole Tool (Weatherford Company), Cross Dipole Wave Sonic Tool (WSTT) (Halliburton Company) or the Dipole Shear Sonic Imager (DSI) (Schlumberger Company).

Figure 3 shows the $V_{\mathrm{P}}, V_{\mathrm{S}}$ velocities and the $V_{\mathrm{p}} / V_{\mathrm{S}}$ ratio measured by the use of the acoustic dipole tool compared with the theoretically calculated $V_{\mathrm{PEQ}}, V_{\mathrm{SEQ}}$ and $V_{\mathrm{PEQ}} / V_{\mathrm{SEQ}}$ values using the
Biot-Gassmann model and the ESTYMACJA TP program (Bała \& Cichy 2005, 2006) as the example for well BX located on the shelf. The $V_{\mathrm{P}}, V_{\mathrm{PEO}}$ curves coincide, the determination coefficient $R^{2}=0.858$. A slightly lower $R^{2}=0.799$ characterizes a $V_{\text {SFast }}$ and $V_{\text {SEQ }}$ dependency. When analyzing the $V_{\mathrm{P}} / V_{\mathrm{S}}$ ratio graph, very disturbed zones can be seen, which may indicate the presence of anisotropy. The range of research in this hole includes the series from the Lower Silurian to the Ordovician limestones. It should be noted that the interpreted values of the interval times $\mathrm{S}_{\text {Fast }}$ and $\mathrm{S}_{\text {slow }}$ slightly differed, the exception being the interval 1698-1705 m (marked by the ellipse in Figure 3), in which the presence of anisotropy of the $S$ wave velocity was observed.

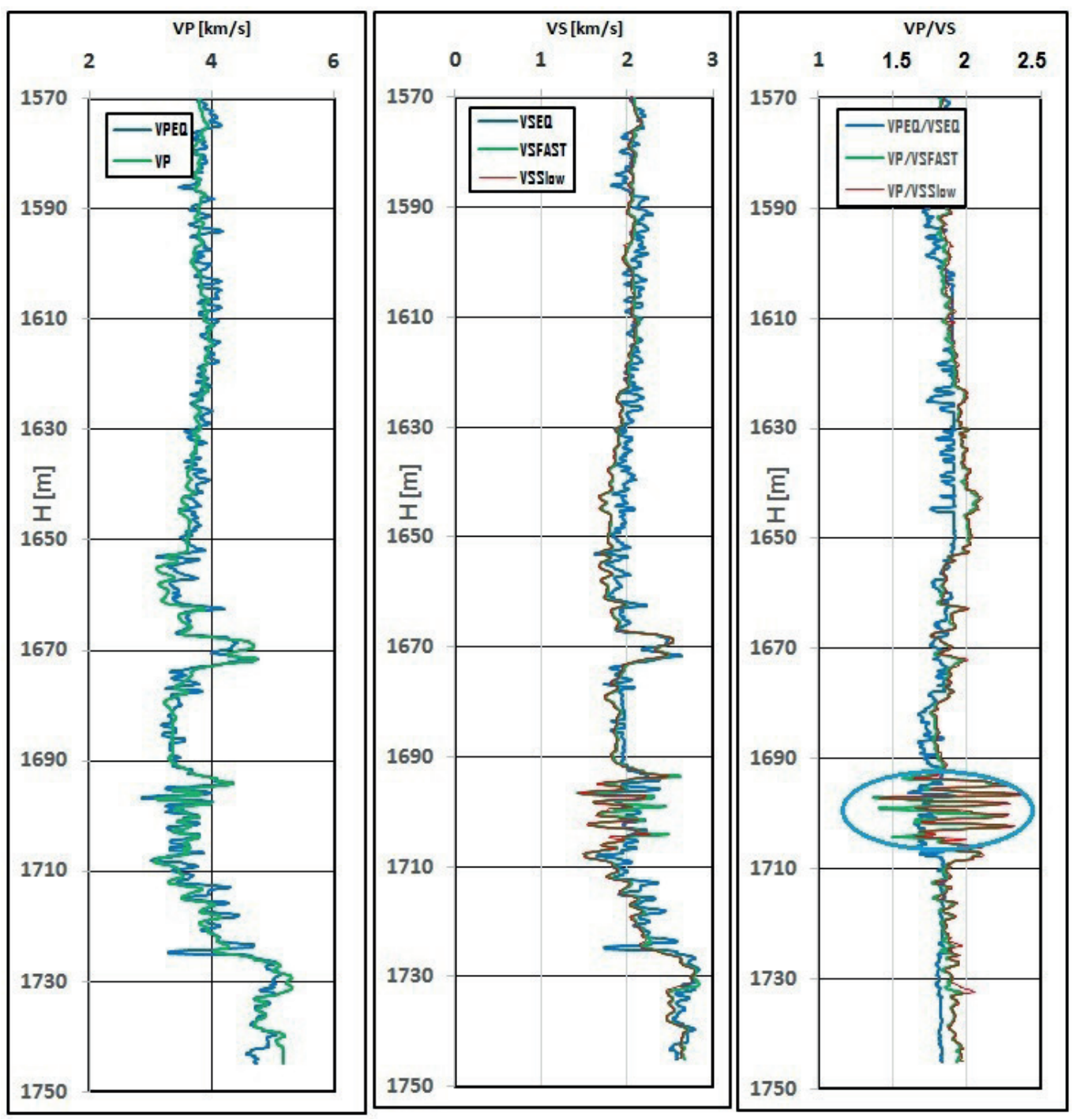

Fig. 3. Comparison of the interpretation results of waveforms recorded with the acoustic dipole probe $\left(V_{P}, V_{\text {SFast }}, V_{\text {SSlow }}\right.$ velocities and $V_{P} / V_{S F a s}, V_{P} / V_{\text {SSlow }}$ ratio) with the values calculated by the $B G$ model $\left(V_{P E Q}\right.$, $V_{S E Q}$ velocities and $V_{P E Q} / V_{S E Q}$ ratio) in the BX well. The interval corresponds to the formations from the Lower Silurian to the Lower Ordovician 
A strong dependence between $V_{P}$ and the volume of clay and kerogen $V_{\text {clay+kerogen }}$ was also observed considering the presence of kerogen (Fig. 4) in well $\mathrm{O} 2$ located in the Baltic Basin. Coefficient of determination $R^{2}$ is equal to 0.71 .

Using the available measurement data, calculations were made for the Silurian and Ordovician shale formations, in all wells, Thomsen pseudo-anisotropy $\varepsilon$, and $\gamma$ using the Li method (2006) and formulas (1), (3), and (4).

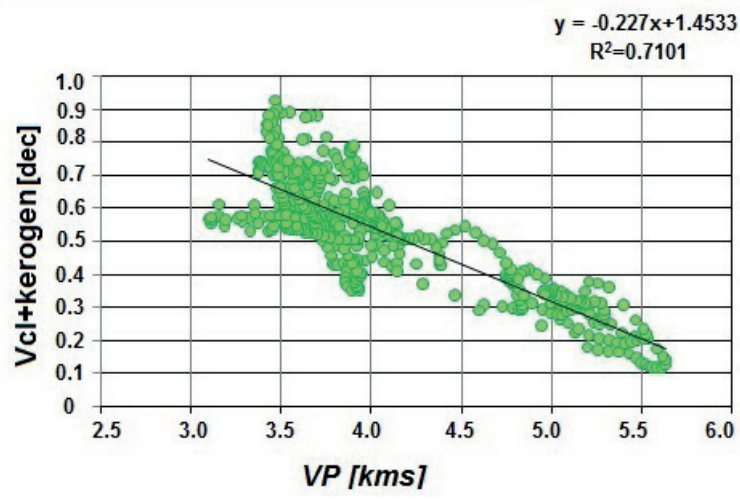

Fig. 4. Plot compressional $\left(V_{P}\right)$ vs volume sum of clay and kerogen $\left(V_{\text {clay+kerogen }}\right)$ in interval: $2867-2935 \mathrm{~m}$ in well O2 (from the Lower Silurian to the Lower Ordovician)

In calculating pseudo-anisotropy parameters $\varepsilon$ and $\gamma$, slightly different velocity values were adopted for the clay points, critical porosity and quartz. The parameters of anisotropy determined in this way were called by the authors of this paper pseudo-anisotropy because the method does not take into account fractures or microfissures. These data were determined on the basis of a detailed analysis of well logging data. It was established that the "Point of the clay" contains the sum of the clay material and kerogen (similar as Zhao et al. 2016).

The values used in points are:

$V_{\text {Pwater }}=1.54 \mathrm{~km} / \mathrm{s}, \quad V_{\text {Pquartz }}=5.98 \mathrm{~km} / \mathrm{s}$, and $V_{\text {Squartz }}=4.03 \mathrm{~km} / \mathrm{s}, V_{\text {Pquartz }} / V_{\text {Squartz }}=1.484$; $V_{\text {Pclay+kerogen }}=3.5 \mathrm{~km} / \mathrm{s}, V_{\text {Sclay+kerogen }}==1.78 \mathrm{~km} / \mathrm{s}$ and $V_{\text {Pclay+kerogen }} / V_{\text {Sclay+kerogen }}=1.97$.

Assuming that the values of the pseudo-anisotropy parameters $\varepsilon$ and $\gamma$ for a series of limestones should be low, $\varepsilon_{\text {clay }}$ and $\gamma_{\text {clay }}$ were chosen so that this condition was met. Assuming $\varepsilon_{\text {clay }}=0.35$ and $\gamma_{\text {clay }}=0.37$, for this series with volume $V_{\text {lime }}>0.65$ the results given in Table 1 were obtained.
Table 1

Parameters of pseudo-anisotropy $\varepsilon$ and $\gamma$ for a series of limestones 3237.0-3249.0 m (well K1)

\begin{tabular}{|c|c|c|c|}
\hline \multicolumn{4}{|c|}{ A series of limestones with an interval 3237.0-3249.0 m } \\
$\begin{array}{c}\left(V_{\text {lime }}>0.65\right) ; \\
\text { number of points }=55\end{array}$ \\
\hline \multicolumn{3}{|c|}{$\varepsilon$} & \multicolumn{2}{c|}{$\gamma$} \\
\hline$\varepsilon_{\mathrm{av}}$ & 0.080 & $\gamma_{\mathrm{av}}$ & 0.069 \\
\hline$\varepsilon_{\min }$ & 0.017 & $\gamma_{\min }$ & 0.015 \\
\hline$\varepsilon_{\max }$ & 0.112 & $\gamma_{\max }$ & 0.111 \\
\hline$\varepsilon_{\text {median }}$ & 0.085 & $\gamma_{\text {median }}$ & 0.072 \\
\hline
\end{tabular}

Wang (2002) presents similar values on the basis of laboratory data for limestone samples (Canadian limestones).

Figure 5 shows the relationships between pseudo-anisotropic parameters $\varepsilon$ and $\gamma$ and the P- and $\mathrm{S}$-wave velocities $V_{\mathrm{P}}, V_{\text {SFast }}$ and the sum of the clay volume and kerogen $V_{\text {clay+kerogen }}$ calculated for the Silurian and Ordovician deposits in well $\mathrm{K} 1$ in interval 3008.5-3249.0 m.

An analysis of the distribution of the points on the graphs (Fig. 5) allows for the formulation of the following conclusions:

- Almost all points are located near the quartz clay+kerogen line. This may indicate a low porosity of these formations. This conclusion is confirmed by the $\varepsilon$ parameter sets with the porosity coefficient determined on the basis of data interpretation of well logs presented for the two wells: $\mathrm{O} 2$ and $\mathrm{K} 1$ (Fig. 6).

- Shifting some points to the right from the quartz - clay+kerogen line is caused by the addition of carbonates, mainly calcite (in the clay formations of the Sasino Formation, the samples have increased amounts of calcite and the presence of ankerite). Since the velocity $V_{\mathrm{P}}$ of the calcite mineral is assumed to be $6.22 \mathrm{~km} / \mathrm{s}$, $V_{\mathrm{S}}=3.44 \mathrm{~km} / \mathrm{s}$ (Schlumberger 1991), this justifies the points in Figure 5A being ejected with the relation $\varepsilon$ vs $V_{\mathrm{P}}$ and the lack or negligible number of the shifted points in Figure $5 \mathrm{~B}$ for the relations $\gamma$ vs $V_{\text {SFast }}$.

Additional boreholes in which the above method was tested are wells L1, O2, W1 and B1 drilled in the Baltic Basin (Fig. 2). Similar calculations were made as in the previously described case. 
A

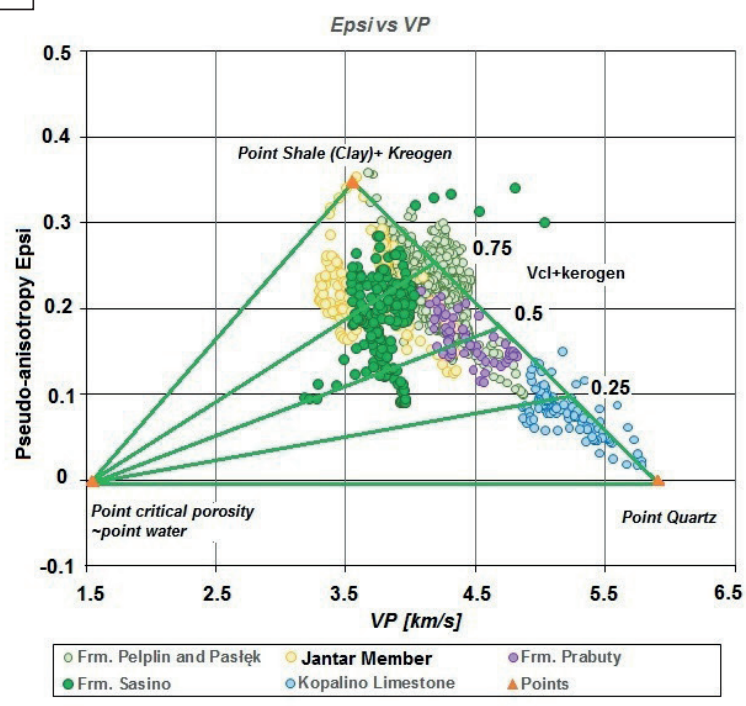

B

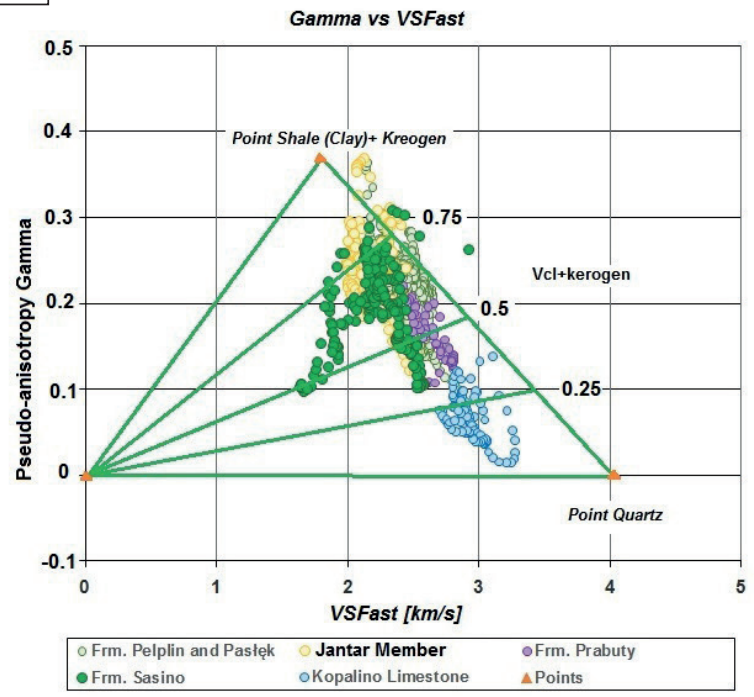

Fig. 5. The relationships between pseudo-anisotropic parameters $\varepsilon$ and $\gamma$ and the $P$-and $S$-wave velocities $\left(V_{P}\right.$ and $\left.V_{\text {SFas }}\right)$ and the sum of the clay volume and kerogen $V_{\text {clay+kerogen }}$ calculated for the Silurian shale and Ordovician shale-mudstone and limestone in well K1

$\mathrm{A}$

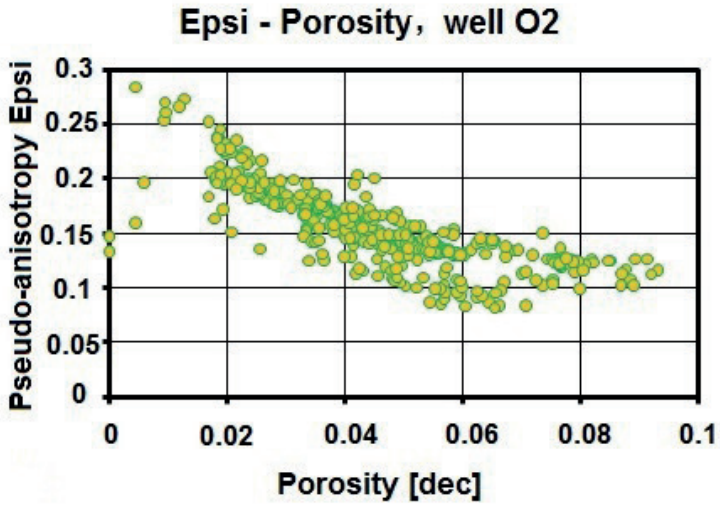

B

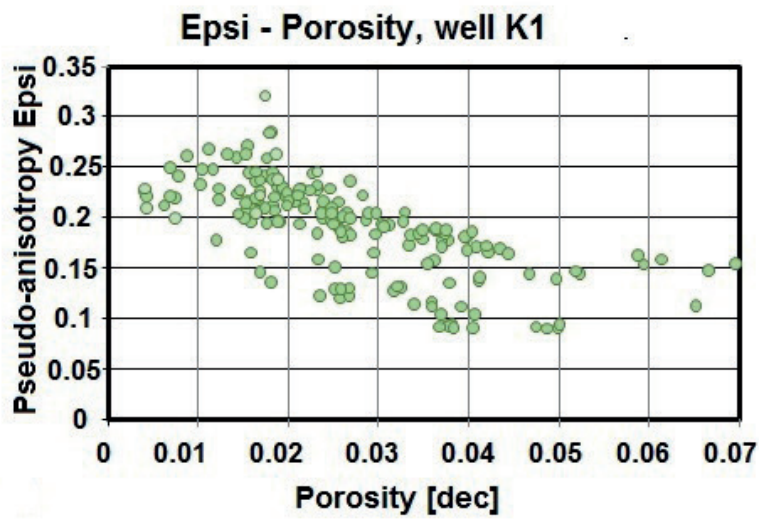

Fig. 6. Dependence of pseudo-anisotropy parameter $\varepsilon$ as a function of porosity for the Silurian and Ordovician shale rocks in wells $\mathrm{O} 2(\mathrm{~A})$ and $\mathrm{K} 1(\mathrm{~B})$

Only in the L1 well was the Thomsen Gamma parameter calculated based on recorded waveform and the interpretation made in the Petrosite system (Halliburton) (Documentation of the borehole). Figure 7A plots the Thomsen pseudo-Gamma parameters calculated using the $\mathrm{Li}$ method (2006) (blue curve) and in the Petrosite system (red curve). In general, the results are fairly good in the interval $2600-2860 \mathrm{~m}$, which is characterized by the same order of magnitude. An increase in the value of Thomsen_Gamma_Hallib. over Thomsen_pseudo-Gamma_cal. can be seen at intervals 2859-2903 $\mathrm{m}$ and 2913-2940 m, corresponding in the lower part to the bituminous claystones from Jantar (2890-2907 m) and the formation of claystones from Sasino (2915-2941 m). The correlation dependence in the interval of the largest divergence of curves (2863-2955 m) shows the existence of some tendency between both parameters (Fig. 7B).

The $\delta$ parameter was not calculated because $c_{13}$ component was not available. 
A

Well L1

Thomsen Gamma Parameter

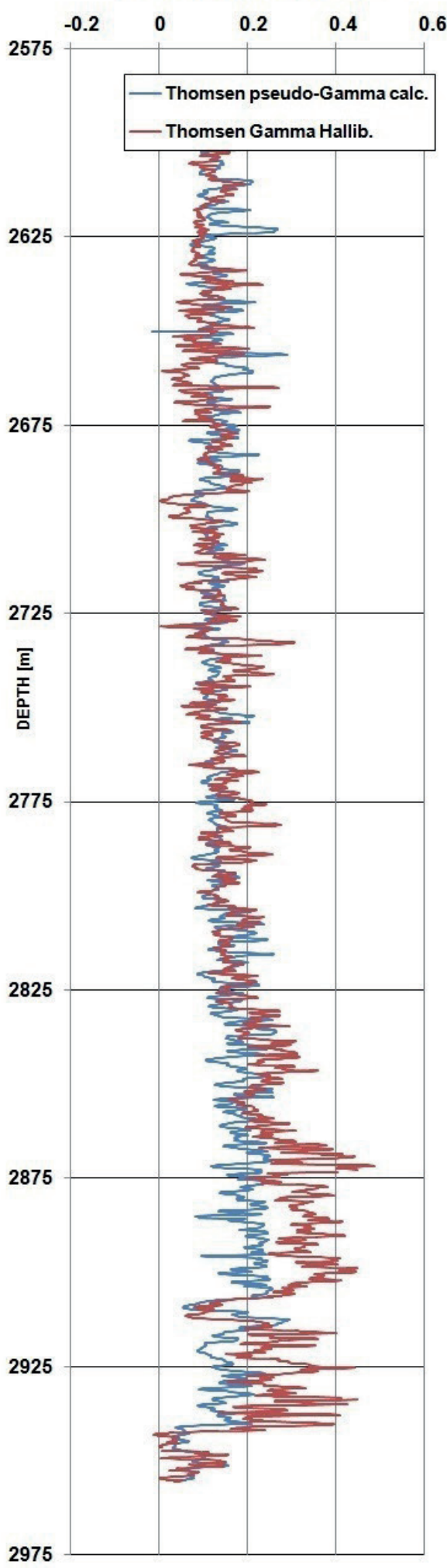

$\mathrm{B}$

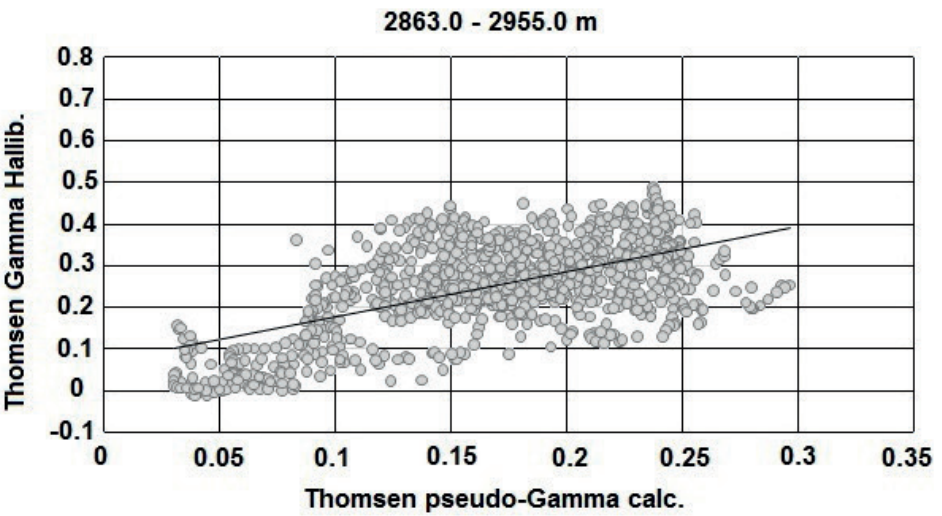

Fig. 7. Comparison of Thomsen pseudo-Gamma parameters calculated using the Li method (2004, 2006) (blue curve) and in the Petrosite system (red curve) in the L1 well (A). Correlation between both parameters $\left(R^{2}=0.46\right)(B)$ 
A DESCRIPTION OF

VARIABILITY OF THE ELASTIC AND RESERVOIR PARAMETERS IN THE SELECTED SILURIAN AND ORDOVICIAN FORMATIONS USING SEMIVARIOGRAMS

The geostatistical analysis of the elastic and reservoir properties $\left(V_{\mathrm{P}}, V_{\text {SFast }}, \varepsilon, \gamma\right.$, porosity (PHI), RHOB (density), $V_{\text {clay }}$ ) was made in order to determine the character of the variability of the selected Silurian and Ordovician formations in wells $\mathrm{K} 1, \mathrm{O} 2, \mathrm{~L} 1, \mathrm{~B} 1$, and $\mathrm{W} 1$.

The structure of the variability of the values of these parameters were analyzed by the geostatistical method of Matheron (1962, 1963), the principles of which are presented in many studies and publications (e.g., Isaaks \& Srivastava 1989, Deutsch 2002, Mucha \& Wasilewska-Błaszczyk 2012).

The geostatistical method can be effectively used if to a certain distance, called the radius of autocorrelation, the values of the regionalized variable are correlated with each other. As part of the geostatistical method, variability is described using the so-called semivariograms that capture the relationship between the variation of the parameter under test (expressed in terms of the mean square of differences) and the average distance between the points of its measurement.

The variability structure of these parameters was analyzed geostatistically using the classical Matheron's semivariogram and relative standardized for variance (for the comparison of the variability structure of these parameters in the selected formations).

In order to quantitatively characterize the degree of continuity of a given deposit parameter, the following was defined:

- The nugget variance $C_{0}$, which expresses local variability and, simultaneously, represents the minimum value of random component of variability. Its value is determined as the value of theoretical semivariogram for a distance between the observation/sampling sites approximating zero.

- The spatial variance $C$, which expresses the maximum value of non-random component of variability in the case of models with asymptote. The share of this value in an overall variability of given parameter determines the maximum size of autocorrelation.

- The range of semivariogram $a$, which shows the maximum range of autocorrelation of given parameter.

- The percentage of the non-random component in the total variability of the parameter:

$w_{N}=\frac{C}{C_{0}+C} \cdot 100 \%$

The calculations of the semivariograms were made using the ISATIS geostatistical software package (www.geovariances.com, Bleinès et al. 2016).

For the geostatistical studies, formations with a thickness greater than $10 \mathrm{~m}$ and with a sampling interval of $0.1 \mathrm{~m}$ were selected to ensure reliable modeling resulting from a sufficient number of pairs of points.

In Table 2, the depth interval and thickness, mean values of porosity, volume of clay and volume of kerogen content in the selected series of Silurian and Ordovician are summarized.

The results of the geostatistical analysis of the structure of the variability of elastic and reservoir parameters $\left(\varepsilon, \gamma\right.$, PHI, $V_{\text {clay }}, V_{\mathrm{P}}$ and $\left.V_{\text {SFast }}\right)$ for the two shale formations in L1, O2, K1, B1 and W1 boreholes located along the NNW-SSE line (see Fig. 2), using the parameters of the geostatistical models matched to the relative semivariograms, are summarized in Table 3.

In Figure 8, for example, the classical Matheron's semivariograms and their spherical theoretical models calculated for the anisotropy parameter $\varepsilon$ in the selected Silurian (A) and Ordovician (B) formations show strong differentiation of the level of variability between the boreholes.

The relative semivariograms of elastic and reservoir properties and the matched theoretical models indicate the different levels and types of parameters variability in the examined boreholes (Fig. 9, Tab. 3). The geostatistical structure of the variability described in the vast majority of cases the spherical theoretical model, occasionally Gaussian and the exponential model (Tab. 3). 


\section{Table 2}

Selected parameters of the analyzed Silurian and Ordovician series

\begin{tabular}{|c|c|c|c|c|c|c|}
\hline Name of well & Stratigraphy & Name of series & $\begin{array}{c}\text { Depth } \\
{[\mathbf{m}]}\end{array}$ & $\begin{array}{c}\text { Porosity } \\
\Phi \\
{[\mathrm{dec}]}\end{array}$ & $\begin{array}{c}V_{\text {clay }} \\
{[\text { dec] }}\end{array}$ & $\begin{array}{c}V_{\text {kerogen }}[\mathrm{dec}] \\
\quad \text { aver. } \\
\max \end{array}$ \\
\hline \multirow{2}{*}{ L1 } & Silurian & Jantar Member & $\begin{array}{c}2895.0-2907.0 \\
12\end{array}$ & 0.086 & 0.61 & $\begin{array}{l}0.053 \\
0.087\end{array}$ \\
\hline & Ordovician & Sasino Formation & $\begin{array}{c}2915.1-2940.7 \\
25.6\end{array}$ & 0.094 & 0.44 & $\begin{array}{l}0.055 \\
0.110\end{array}$ \\
\hline \multirow{2}{*}{$\mathrm{O} 2$} & Silurian & Jantar Member & $\begin{array}{c}2871.0-2884.0 \\
13\end{array}$ & 0.030 & 0.62 & $\begin{array}{l}0.073 \\
0.160\end{array}$ \\
\hline & Ordovician & Sasino Formation & $\begin{array}{c}2892.2-2917.5 \\
25.3\end{array}$ & 0.052 & 0.51 & $\begin{array}{l}0.053 \\
0.165\end{array}$ \\
\hline \multirow{2}{*}{ K1 } & Silurian & Jantar Member & $\begin{array}{c}3198.1-3212.0 \\
13.9\end{array}$ & 0.017 & 0.71 & $\begin{array}{l}0.061 \\
0.149\end{array}$ \\
\hline & Ordovician & Sasino Formation & $\begin{array}{c}3217.6-3236.8 \\
19.2\end{array}$ & 0.028 & 0.61 & $\begin{array}{l}0.050 \\
0.170\end{array}$ \\
\hline \multirow{2}{*}{ B1 } & Silurian & Jantar Member & $\begin{array}{c}3680.0-3693.9 \\
13.9\end{array}$ & 0.047 & 0.52 & $\begin{array}{l}0.066 \\
0.163\end{array}$ \\
\hline & Ordovician & Sasino Formation & $\begin{array}{c}3701.1-3715.8 \\
14.7\end{array}$ & 0.055 & 0.49 & $\begin{array}{l}0.062 \\
0.184\end{array}$ \\
\hline \multirow{2}{*}{ W1 } & Silurian & Jantar Member & $\begin{array}{c}3937.5-3951.0 \\
13.5\end{array}$ & 0.039 & 0.59 & $\begin{array}{l}0.022 \\
0.040\end{array}$ \\
\hline & Ordovician & Sasino Formation & $\begin{array}{c}3958.0-3975.0 \\
17.0\end{array}$ & 0.060 & 0.53 & $\begin{array}{l}0.036 \\
0.066\end{array}$ \\
\hline
\end{tabular}

$\mathrm{A}$

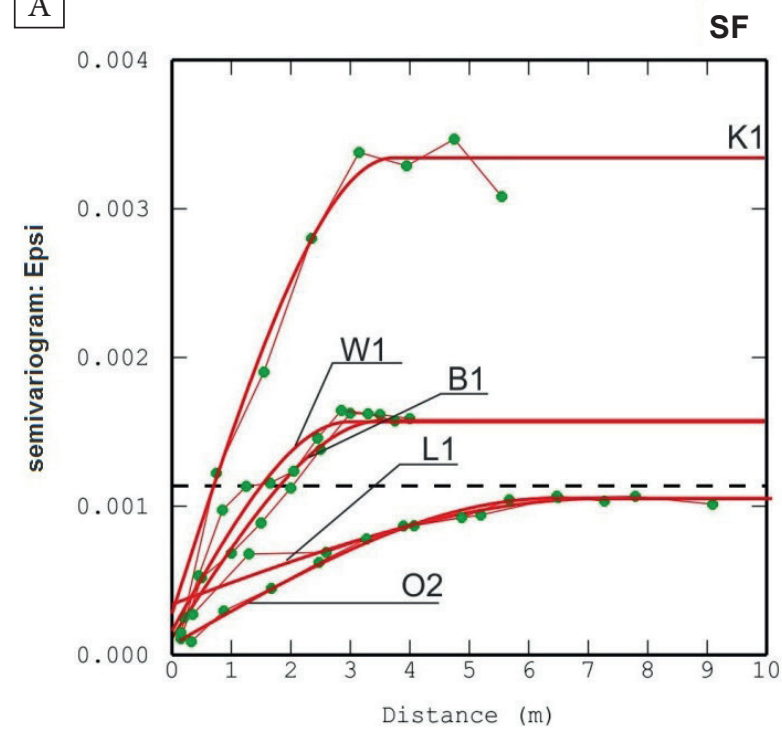

B

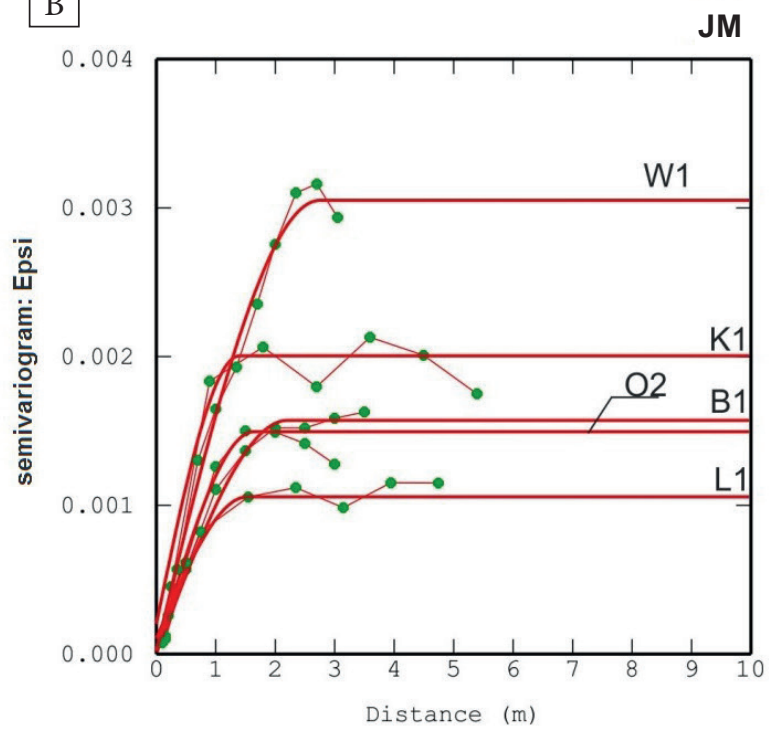

Fig. 8. Example of Matheron's semivariograms calculated for parameter $\varepsilon$ for the selected Jantar Member (A) and Sasino Formation (B) and their theoretical (spherical) models (boreholes K1, O2, L1, B1 and W1)

The form of the spherical model describes the equation: semivariogram $=C_{0}+C_{\text {sph }}(h / a)$. The spherical model is one of the most commonly used in geostatistics for the spatial structure characteristics. In the initial section, the spherical model has the character of a linear function with a slope of $3 C / 2 a$, where $C$ denotes the variance of the non-random component of the parameter variability (sill) and $a$ is the range of the semivariogram or autocorrelation (Stach 2009). 

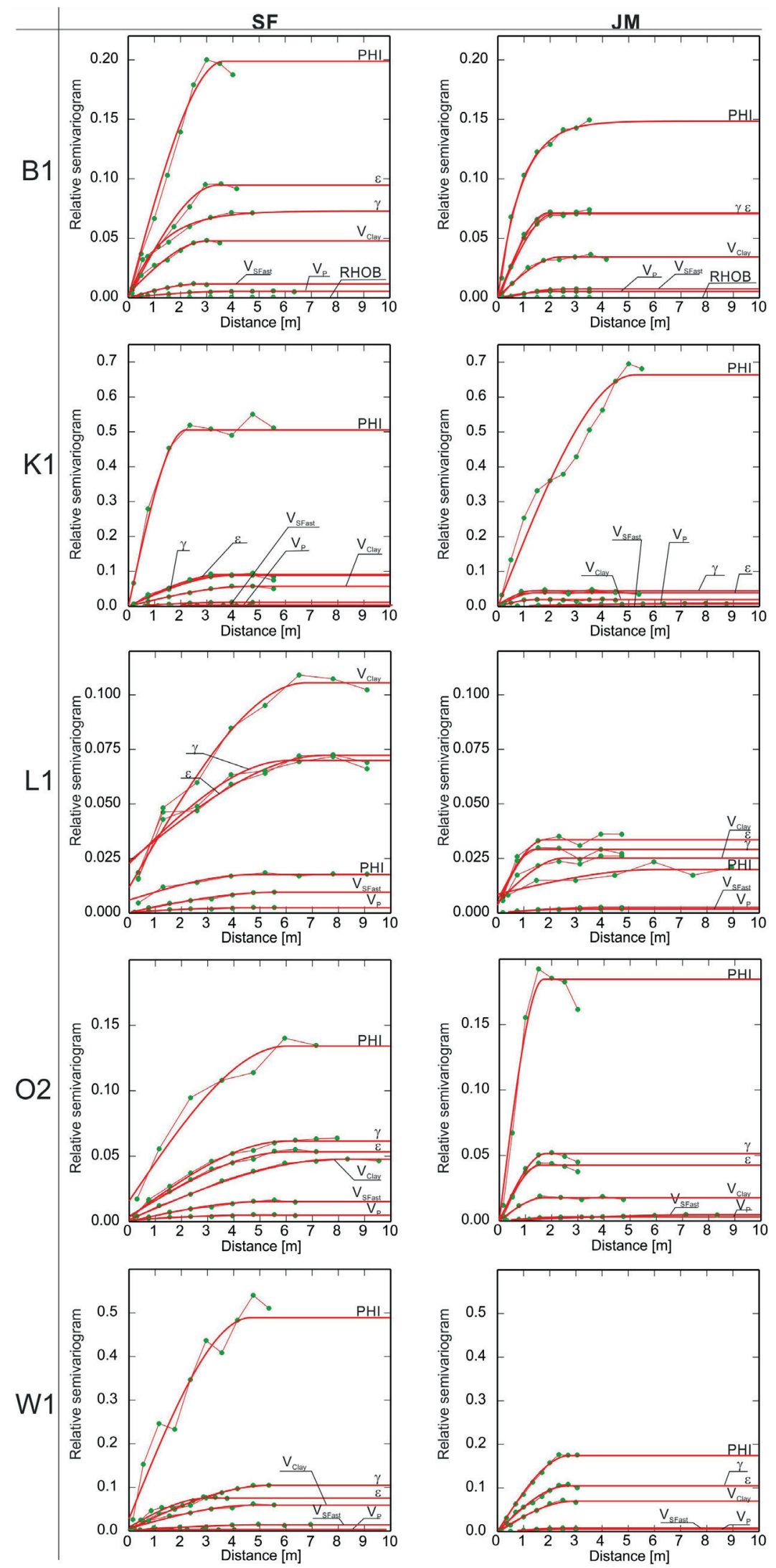

Fig. 9. Relative semivariograms and theoretical models (red) calculated for parameters $\varepsilon, \gamma, P H I, V_{p}, V_{S F a s t}$ and $V_{\text {clay }}$ for the Silurian and Ordovician series (Sasino Formation and Jantar Member) 
The share of the non-random component of often significantly above 80\%) (Tab. 3, Figs. 9, 10). the variability $\left(w_{N}\right)$ of these parameters in the investigated formations is strongly marked (most

The range of semivariograms varies from about 1 to $8 \mathrm{~m}$.

\section{Table 3}

List of parameters of theoretical models fitted to relative semivariograms for parameters $\varepsilon, \gamma, P H I, V_{\text {clay, }}, V_{P}$, and $V_{\text {SFast }}$ for the Silurian and Ordovician series (the Jantar Member and Sasino Formation)

\begin{tabular}{|c|c|c|c|c|c|c|c|c|c|}
\hline \multirow{2}{*}{$\begin{array}{l}\text { Name } \\
\text { of well }\end{array}$} & \multirow{2}{*}{ Series } & \multirow{2}{*}{ Parameter } & \multirow{2}{*}{$\begin{array}{l}\text { Type of theoret- } \\
\text { ical model }\end{array}$} & \multicolumn{4}{|c|}{ Parameters of theoretical model } & \multirow{2}{*}{$w_{N}[\%]$} & \multirow{2}{*}{$v[\%]$} \\
\hline & & & & $C_{0}$ & C & $C_{0}+C$ & $a$ & & \\
\hline \multirow{14}{*}{ B1 } & \multirow{7}{*}{$\begin{array}{l}\text { Sasino } \\
\text { Formation }\end{array}$} & $\varepsilon$ & spherical & 0 & 0.09456 & 0.09456 & 3.42 & 100.0 & 25.9 \\
\hline & & $\gamma$ & exponential & $1.562 \mathrm{E}-04$ & 0.07265 & 0.07281 & 3.79 & 99.8 & 25.6 \\
\hline & & PHI & spherical & 0 & 0.20570 & 0.20570 & 3.66 & 100.0 & 41.8 \\
\hline & & RHOB & spherical & 0 & 0.00057 & 0.00057 & 3.95 & 100.0 & 2.3 \\
\hline & & $V_{\text {clay }}$ & spherical & $3.473 \mathrm{E}-03$ & 0.04433 & 0.04780 & 3.05 & 92.7 & 18.9 \\
\hline & & $V_{\mathrm{P}}$ & spherical & $1.919 \mathrm{E}-04$ & 0.00527 & 0.00546 & 3.93 & 96.5 & 6.6 \\
\hline & & $V_{\text {SFast }}$ & spherical & 0 & 0.01147 & 0.01147 & 2.74 & 100.0 & 10.7 \\
\hline & \multirow{7}{*}{$\begin{array}{l}\text { Jantar } \\
\text { Member }\end{array}$} & $\varepsilon$ & spherical & $1.601 \mathrm{E}-04$ & 0.07050 & 0.07066 & 2.14 & 99.8 & 27.0 \\
\hline & & $\gamma$ & spherical & $2.413 \mathrm{E}-04$ & 0.07102 & 0.07126 & 1.94 & 99.7 & 26.2 \\
\hline & & PHI & exponential & 0 & 0.14850 & 0.14850 & 2.69 & 100.0 & 40.6 \\
\hline & & RHOB & spherical & 0 & 0.00030 & 0.00030 & 2.47 & 100.0 & 2.0 \\
\hline & & $V_{\text {clay }}$ & spherical & $8.010 \mathrm{E}-04$ & 0.03350 & 0.03430 & 2.41 & 97.7 & 17.2 \\
\hline & & $V_{\mathrm{P}}$ & spherical & 0 & 0.00541 & 0.00541 & 2.09 & 100.0 & 6.6 \\
\hline & & $V_{\text {SFast }}$ & gausian & 0 & 0.00740 & 0.00740 & 2.24 & 100.0 & 7.1 \\
\hline \multirow{12}{*}{ K1 } & \multirow{6}{*}{$\begin{array}{l}\text { Sasino } \\
\text { Formation }\end{array}$} & $\varepsilon$ & spherical & $2.772 \mathrm{E}-04$ & 0.09074 & 0.09102 & 3.70 & 99.7 & 27.6 \\
\hline & & $\gamma$ & spherical & $2.432 \mathrm{E}-04$ & 0.08799 & 0.08823 & 3.94 & 99.7 & 25.4 \\
\hline & & PHI & spherical & 0 & 0.50520 & 0.50520 & 2.20 & 100.0 & 68.9 \\
\hline & & $V_{\text {clay }}$ & spherical & $2.592 \mathrm{E}-04$ & 0.05690 & 0.05716 & 4.65 & 99.5 & 20.3 \\
\hline & & $V_{\mathrm{P}}$ & spherical & $2.578 \mathrm{E}-04$ & 0.00288 & 0.00314 & 2.85 & 91.8 & 5.4 \\
\hline & & $V_{\text {SFast }}$ & spherical & 0 & 0.01175 & 0.01175 & 4.10 & 100.0 & 10.7 \\
\hline & \multirow{6}{*}{$\begin{array}{l}\text { Jantar } \\
\text { Member }\end{array}$} & $\varepsilon$ & spherical & $2.005 \mathrm{E}-04$ & 0.03886 & 0.03906 & 1.40 & 99.5 & 20.0 \\
\hline & & $\gamma$ & spherical & $5.596 \mathrm{E}-03$ & 0.03933 & 0.04493 & 1.38 & 87.5 & 20.8 \\
\hline & & PHI & spherical & 0 & 0.66370 & 0.66370 & 5.25 & 100.0 & 76.2 \\
\hline & & $V_{\text {clay }}$ & spherical & 0 & 0.01975 & 0.01975 & 1.43 & 100.0 & 13.1 \\
\hline & & $V_{\mathrm{P}}$ & spherical & $5.381 \mathrm{E}-04$ & 0.00854 & 0.00908 & 7.97 & 94.1 & 7.4 \\
\hline & & $V_{\text {SFast }}$ & spherical & 0 & 0.00710 & 0.00710 & 7.37 & 100.0 & 6.6 \\
\hline \multirow{12}{*}{ L1 } & \multirow{6}{*}{$\begin{array}{l}\text { Sasino } \\
\text { Formation }\end{array}$} & $\varepsilon$ & spherical & $2.372 \mathrm{E}-02$ & 0.04861 & 0.07233 & 7.55 & 67.2 & 23.8 \\
\hline & & $\gamma$ & spherical & $2.266 \mathrm{E}-02$ & 0.04726 & 0.06992 & 6.08 & 67.6 & 23.1 \\
\hline & & PHI & spherical & $5.959 \mathrm{E}-03$ & 0.01162 & 0.01758 & 4.72 & 66.1 & 12.9 \\
\hline & & $V_{\text {clay }}$ & spherical & 1.195E-02 & 0.09505 & 0.10700 & 6.78 & 88.8 & 29.4 \\
\hline & & $V_{\mathrm{P}}$ & spherical & $3.127 \mathrm{E}-04$ & 0.00212 & 0.00243 & 4.46 & 87.1 & 4.1 \\
\hline & & $V_{\text {SFast }}$ & spherical & $2.896 \mathrm{E}-04$ & 0.00921 & 0.00950 & 5.58 & 97.0 & 9.1 \\
\hline & \multirow{6}{*}{$\begin{array}{l}\text { Jantar } \\
\text { Member }\end{array}$} & $\varepsilon$ & spherical & $5.915 \mathrm{E}-03$ & 0.02762 & 0.03354 & 1.79 & 82.4 & 18.1 \\
\hline & & $\gamma$ & spherical & $3.509 \mathrm{E}-03$ & 0.02565 & 0.02916 & 1.44 & 88.0 & 16.3 \\
\hline & & PHI & spherical & $8.575 \mathrm{E}-03$ & 0.01131 & 0.01989 & 6.05 & 56.9 & 12.7 \\
\hline & & $V_{\text {clay }}$ & spherical & $4.869 \mathrm{E}-03$ & 0.02028 & 0.02515 & 2.55 & 80.6 & 14.9 \\
\hline & & $V_{\mathrm{P}}$ & spherical & 0 & 0.00254 & 0.00254 & 3.90 & 100.0 & 4.6 \\
\hline & & $V_{\text {SFast }}$ & spherical & $1.387 \mathrm{E}-04$ & 0.00161 & 0.00175 & 3.04 & 92.1 & 4.2 \\
\hline
\end{tabular}


Table 3 cont.

\begin{tabular}{|c|c|c|c|c|c|c|c|c|c|}
\hline \multirow{14}{*}{$\mathrm{O} 2$} & \multirow{7}{*}{$\begin{array}{l}\text { Sasino } \\
\text { Formation }\end{array}$} & $\varepsilon$ & spherical & $4.105 \mathrm{E}-03$ & 0.04924 & 0.05335 & 6.10 & 92.3 & 19.4 \\
\hline & & $\gamma$ & spherical & $3.398 \mathrm{E}-03$ & 0.05814 & 0.06154 & 6.05 & 94.5 & 21.4 \\
\hline & & PHI & spherical & $1.592 \mathrm{E}-02$ & 0.11820 & 0.13412 & 6.02 & 88.1 & 33.9 \\
\hline & & RHOB & spherical & 0 & 0.00077 & 0.00077 & 6.49 & 100.0 & 2.5 \\
\hline & & $V_{\text {clay }}$ & spherical & $1.535 \mathrm{E}-03$ & 0.04618 & 0.04772 & 8.03 & 96.8 & 18.0 \\
\hline & & $V_{\mathrm{P}}$ & spherical & $9.103 \mathrm{E}-04$ & 0.00402 & 0.00493 & 4.36 & 81.5 & 6.2 \\
\hline & & $V_{\text {SFast }}$ & spherical & $2.676 \mathrm{E}-04$ & 0.01514 & 0.01541 & 5.20 & 98.3 & 12.7 \\
\hline & \multirow{7}{*}{$\begin{array}{l}\text { Jantar } \\
\text { Member }\end{array}$} & $\varepsilon$ & spherical & $1.209 \mathrm{E}-04$ & 0.04242 & 0.04254 & 1.57 & 99.7 & 18.9 \\
\hline & & $\gamma$ & spherical & $1.997 \mathrm{E}-04$ & 0.05126 & 0.05146 & 1.79 & 99.6 & 20.1 \\
\hline & & PHI & spherical & 0 & 0.18460 & 0.18460 & 1.69 & 100.0 & 39.8 \\
\hline & & RHOB & spherical & 0 & 0.00043 & 0.00043 & 8.46 & 100.0 & 1.6 \\
\hline & & $V_{\text {clay }}$ & spherical & $6.154 \mathrm{E}-04$ & 0.01757 & 0.01819 & 1.72 & 96.6 & 12.6 \\
\hline & & $V_{\mathrm{P}}$ & spherical & 0 & 0.00310 & 0.00310 & 2.70 & 100.0 & 5.2 \\
\hline & & $V_{\text {SFast }}$ & spherical & 0 & 0.00475 & 0.00475 & 7.92 & 100.0 & 5.3 \\
\hline \multirow{12}{*}{ W1 } & \multirow{6}{*}{$\begin{array}{l}\text { Sasino } \\
\text { Formation }\end{array}$} & $\varepsilon$ & spherical & $8.748 \mathrm{E}-03$ & 0.06669 & 0.07544 & 3.00 & 88.4 & 26.8 \\
\hline & & $\gamma$ & spherical & $4.423 \mathrm{E}-03$ & 0.10010 & 0.10452 & 5.41 & 95.8 & 26.1 \\
\hline & & PHI & spherical & $2.778 \mathrm{E}-02$ & 0.46140 & 0.48918 & 4.67 & 94.3 & 56.5 \\
\hline & & $V_{\text {clay }}$ & spherical & $5.667 \mathrm{E}-03$ & 0.05350 & 0.05917 & 4.76 & 90.4 & 20.1 \\
\hline & & $V_{\mathrm{P}}$ & spherical & 0 & 0.00371 & 0.00371 & 1.31 & 100.0 & 6.1 \\
\hline & & $V_{\text {SFast }}$ & spherical & $1.415 \mathrm{E}-03$ & 0.01267 & 0.01409 & 5.02 & 90.0 & 10.4 \\
\hline & \multirow{6}{*}{$\begin{array}{l}\text { Jantar } \\
\text { Member }\end{array}$} & $\varepsilon$ & spherical & $2.900 \mathrm{E}-04$ & 0.10470 & 0.10499 & 2.70 & 99.7 & 31.5 \\
\hline & & $\gamma$ & spherical & $3.899 \mathrm{E}-04$ & 0.10420 & 0.10459 & 2.71 & 99.6 & 30.7 \\
\hline & & PHI & spherical & 0 & 0.17450 & 0.17450 & 2.78 & 100.0 & 41.2 \\
\hline & & $V_{\text {clay }}$ & spherical & 0 & 0.06981 & 0.06981 & 2.92 & 100.0 & 24.2 \\
\hline & & $V_{\mathrm{P}}$ & gaussian & $1.264 \mathrm{E}-04$ & 0.00534 & 0.00547 & 2.34 & 97.7 & 6.0 \\
\hline & & $V_{\text {SFast }}$ & gaussian & $1.000 \mathrm{E}-04$ & 0.00807 & 0.00817 & 2.36 & 98.8 & 6.9 \\
\hline
\end{tabular}

Explanations: $a$ - semivariogram range, $C_{0}$ - nugget effect, $C$ - sill, $w_{N}$ - share of the non-random component of the variability, $v-$ coefficient of variation.

The level of variation of the elastic and reservoir parameters in geostatistical terms (expressed by the amplitude of the relative semivariogram model $C_{0}+C$ ) is correlated with the statistical level of their variability, expressed in the coefficient of variation $v$ (Fig. 10):

$v=\frac{s}{\bar{x}} \cdot 100 \%$

where:

$s$ - standard deviation of the parameter,

$\bar{x}$ - mean value of the parameter.

It can be expected that the parameters characterized by the higher amplitudes of the semivariogram models will be characterized by the larger errors of their estimation using geostatistical methods. The coefficients of variability $(v)$ of the analyzed parameters indicate generally low or intermediate variability (they range from 5\% to $40 \%$ ), the exception is porosity, which is characterized by high variability and reaches $76 \%$ in maximum.

The ranges of the semivariograms of a given parameter in both formations in the tested boreholes as well as comparing the ranges of the semivariograms in a given series in different wells usually present large variations (Figs. 9, 10). The amplitudes of the semivariograms $\left(C_{0}+C\right)$ of a given parameter in boreholes are also significantly different. Therefore, it is not possible to formulate a generalized model of variability of elastic parameters, characterizing the structure of the variability of a given parameter in all boreholes.

The level of autocorrelation (described by the ranges of the semivariograms (a)) characterizing Ordovician formation parameters are usually significantly higher than in the case of Silurian formation. 

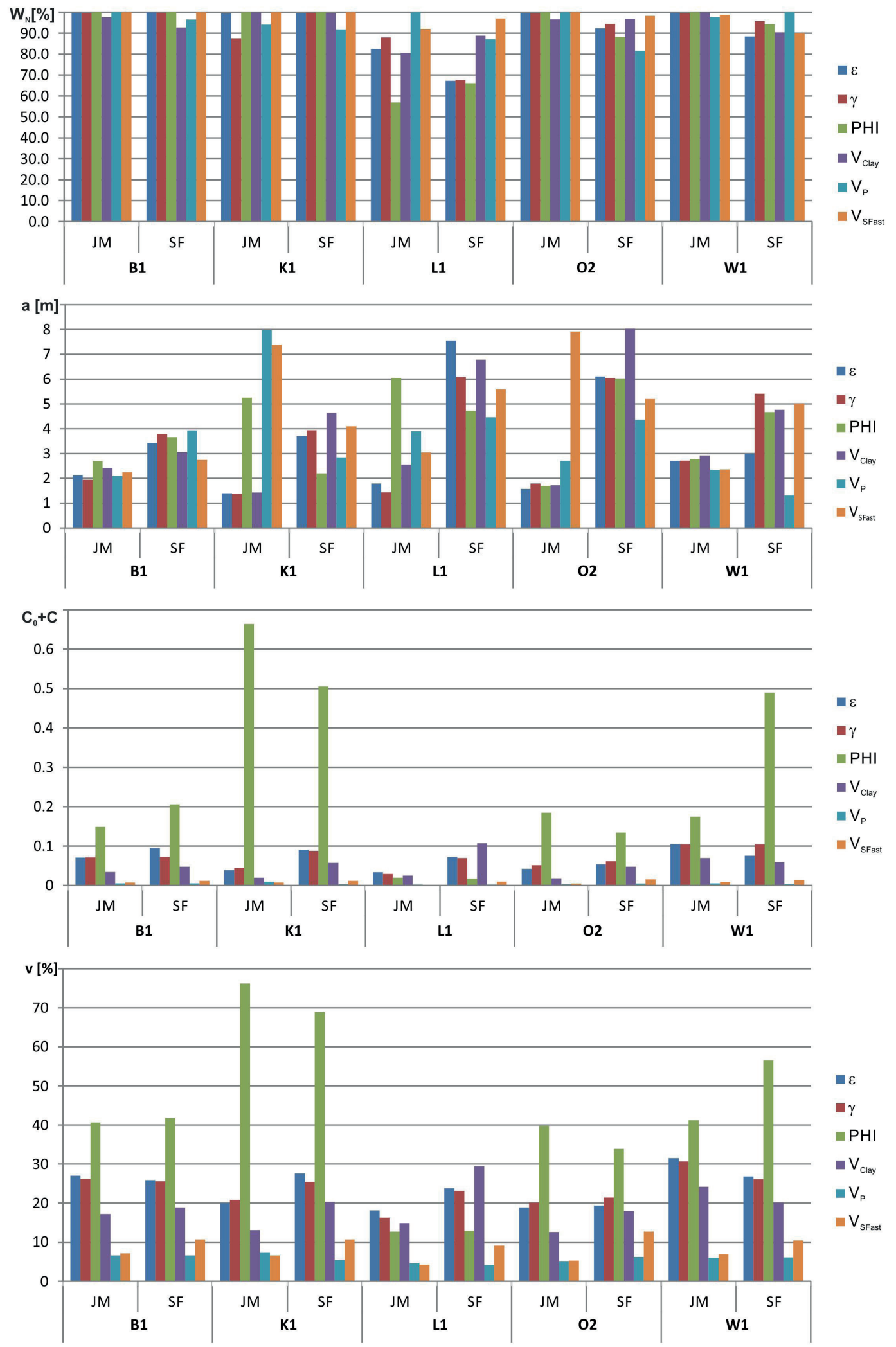

Fig. 10. Summary of maximum non-random components of variability $\left(w_{N}\right)$, ranges of semivariograms (a), amplitudes of semivariograms $\left(C_{0}+C\right)$ and coefficients of variation $(v)$ for parameters $\varepsilon, \gamma, P H I, V_{P}, V_{\text {SFast }}$ and $V_{\text {clay }}$ for the Silurian and Ordovician series (the Sasino Formation and Jantar Member) 


\section{CONCLUSIONS}

- The applied method (Li 2004, 2006) is an attempt to evaluate the parameters of elastic anisotropy in Silurian and Ordovician shale deposits in several boreholes lying in the Baltic basin.

- The measurements of well logging data, and in particular the data recorded with acoustic dipole tools, made it possible to determine the velocity of the longitudinal $\mathrm{P}$ and the shear waves of $S_{\text {Fast }}$ and $S_{\text {Slow }}$ and to calculate the pseudo-anisotropy parameters $\varepsilon$ and $\gamma$.

- The obtained results compared with the results for similargas-bearing shale, published in theliterature, confirmed the correctness of the method and the similarity of the variability range of $\varepsilon$ and $\gamma$ parameters (for example Wang 2002).

- Geostatistical analyzes of the variations in the vertical direction of the parameters, in the selected series of gas-bearing shale, considered as sweet spots, in boreholes K1, L1, O2, B1 and W1 were made only for data from well logging.

- Geostatistical modeling proved the presence in the structure of the variability of the elastic and reservoir parameters, besides the random component, strongly marked non-random component. The maximum share of the non-random component in the parameter variability exceeds $50 \%$, while in most of the analyzed cases it reaches $100 \%$ (Tab. 3).

- The structure of the variability of all of the parameters in most of the analyzed cases can be approximated by a spherical theoretical model. Autocorrelation of the observations usually occurs at distances over 1-5 m. This means that changes in parameter values in the vertical direction are continuous).

- The share of the non-random component of the variability of the elastic and reservoir parameters and the ranges of semivariograms are significant that it is possible to use a geostatistical kriging procedure to estimate their value.

\section{REFERENCES}

Allan A.M., Kanitpanyacharoen W. \& Vanorio T., 2015. A multiscale methodology for the analysis of velocity anisotropy in organic-rich shale. Geophysics, 80, 4, c73-c88, DOI: 10.1190/geo2014-0192.1.
Bandyopadhyay K., 2009. Seismic anisotropy: Geological causes and its implications to reservoir geophysics. Stanford University [Ph.D. thesis].

Bała M. \& Cichy A., 2005. Comparison of P- and S-waves velocities estimated from Biot-Gassmann and Kuster-Toksöz models with results obtained from acoustic wavetrains interpretation. Acta Geophysica, 55, 2, 222-230.

Bała M. \& Cichy A., 2006. Metody obliczania prędkości fal $P$ i S na podstawie modeli teoretycznych i danych geofizyki otworowej - program ESTYMACJA [Methods of calculating $P$ and $S$ waves velocities as a function based on theoretical models and well logging data - Programme ESTYMACJA]. Uczelniane Wydawnictwa Naukowo-Dydaktyczne AGH, Kraków.

Bała M., 2007. Wpływ obecności iłów, porowatości oraz nasycenia porów wodą i gazem na parametry sprężyste skał zbiornikowych określanych na podstawie teoretycznych modeli ośrodków porowatych i danych geofizyki wiertniczej [Effects of shale content, porosity and water- and gas-saturation in pores on elastic parameters of reservoir rocks based on theoretical models of porous media and well-logging data. Przegląd Geologiczny, 55, $1,46-53$.

Bała M., 2009. Badanie wpływu anizotropii i zailenia na prędkości rozchodzenia się fal podłużnych i poprzeczych oraz innych parametrów sprężystych skał klastycznych [Study of the effect of anisotropy and shaliness on velocities of longitudinal and shear waves and other elastic parameters of clastic rocks]. Geologia: kwartalnik Akademii Górniczo-Hutniczej im. Stanisława Staszica $w$ Krakowie, 35, 2/1, 559-566.

Bała M., 2011. Evaluation of electric parameters of anisotropic sandy-shaly Miocene formations on the basis of resistivity logs. Acta Geophysica, 59, 5, 954-966, DOI: https:// doi.org/10.2478/s11600-011-0033-1.

Bała M. \& Cichy A., 2015. Evaluating Electrical Anisotropy Parameters in Miocene Formations in the Cierpisz Deposit. Acta Geophysica, 63, 5, 1296-1315.

Banik N.C., 1987. An effective anisotropy parameter in transversely isotropic media. Geophysics, 52, 12, 1654-1664.

Bayuk I.O., Ammerman M. \& Chesnokov E.M., 2007. Elastic moduli of anisotropic clay. Geophysics, 72, 5, D107-D117. DOI: https://doi.org/10.1190/1.2757624.

Bleinès C., Bourges M., Deraisme J., Geffroy F., Jeannée N., Lemarchand O., Perseval S., Rambert F., Renard D., Touffait Y. \& Wagner L., 2016. Isatis Technical References. Geovariances.

Carcione J.M., Helle H.B. \& Avseth P., 2011. Source-rock seismic-velocity models: Gassmann versus Backus. Geophysics, 76, 5, N37-N45. DOI: 10.1190/geo2010-0258.1.

Castagna J.P., Batzle M.E. \& Eastwood R.L., 1985. Relationship between the compressional-wave and shear-wave velocities in clastic silicate rocks. Geophysics, 50, 4, 571-581.

Deutsch C.V., 2002. Geostatistical Reservoir Modeling. Oxford University Press, New York.

Eastwood R.L. \& Castagna J.P., 1983. Basic for interpretation of $\mathrm{Vp} / \mathrm{Vs}$ ratios in complex lithologies. [in:] Transactions of the SPWLA 24th Annual Logging Symposium, June 27-30, Calgary, Alberta, Society of Professional Well Log Analysts, paper G, 1-18. 
Han D.H., Nur A. \& Morgan D., 1986. Effects of porosity and clay content on wave velocities in sandstones. Geophysics, 51, 11, 2093-2107.

Hornby B.E., Schwartz L.M. \& Hudson J.A., 1994. Anisotropic effective-medium modeling of the elastic properties of shales. Geophysics, 59, 10, 1570-1583.

Horne S., Walsh J. \& Miller D., 2012. Elastic anisotropy in the Haynesville Shale from dipole sonic data. First Break, 30, 37-41.

Isaaks E.H. \& Srivastava R.M., 1989. An Introduction to Applied Geostatistics. Oxford University Press, New York.

Isatis, 2017. Software: www.geovariances.com.

Johnston J.E. \& Christensen N.I., 1995. Seismic anisotropy of shales. Journal of Geophysical Research, 100, B4, 5991-6003. DOI: 10.1029/95JB00031.

Katahara K.W., 1996. Clay mineral elastic properties. [in:] 1996 SEG Annual Meeting, 10-15 November, Denver, Colorado, Society of Exploration Geophysicists, 1691-1694.

Li Y., 2004. Anisotropic Parameter Prediction in Clastic Rocks. CSEG National Convention Great Explorations, Canada and Beyond.

Li Y., 2006. An empirical method for estimation of anisotropic parameters in clastic rocks. The Leading Edge, June, 706-711.

Marion D., Nur A. \& Han D.H., 1992. Compressional velocity and porosity in sand-clay mixtures. Geophysics, 52, $4,554-563$.

Matheron G., 1962. Traité de géostatistique appliquée. Tome 1. Mémoires du BRGM (Paris), 14, Éditions Technip, Paris.

Matheron G., 1963. Traité de géostatistique appliquée. Tome 2. Mémoires du BRGM (Paris), 24, Éditions Technip, Paris.

Mavko G., Mukerji T. \& Dvorkin J., 2009. Rock Physics Handbook: Tools for Seismic Analysis in Porous Media. $2^{\text {nd }}$ ed. Cambridge University Press, Cambridge.

Mondol N., Jahren J., Bjorlykke K. \& Brevik I., 2008. Elastic properties of clay minerals. The Leading Edge, 27, 6758-6770.

Mucha J. \& Wasilewska-Błaszczyk M., 2012. Variability anisotropy of mineral deposits parameters and its impact on resources estimation - a geostatistical approach. Gospodarka Surowcami Mineralnymi, 28, 4, 113-135. DOI: 10.2478/v10269-012-0037-8.

Prasad M., Kopycinska M., Rabe U. \& Arnold W., 2002. Measurement of Young's modulus of clay minerals using atomic force acoustic microscopy. Geophysical Research Letters, 29, 8, 13-1-13-4.

Ryan-Grigor S., 1997. Empirical relationships between transverse isotropy parameters and $V_{p} / V_{S}$ : implications for AVO. Geophysics, 62, 5, 1359-1364.

Sato H., Ono K., Johnston C.T. \& Yamagishi A., 2005. First-principles studies on elastic constants of a 1:1 layered kaolinite mineral. American Mineralogist, 90, 11-12, 1824-1826.

Sayers C.M., 2005. Seismic anisotropy of shales. Geophysical Prospecting, 53, 667-676.
Sayers C.M., 2013. The effect of kerogen on the elastic anisotropy of organic-rich shales. Geophysics, 78, 2, D65-D74. DOI: 10.1190/geo2012-0309.1.

Sondergeld C.H. \& Rai C.S., 2011. Elastic anisotropy of shales. The Leading Edge, 30, 3, 324-331.

Sone H. \& Zoback M.D., 2013. Mechanical properties of shale gas reservoir rocks, Part 1: Static and dynamic elastic properties and anisotropy. Geophysics, 8, 5, D381-D392. DOI: 10.1190/geo2013-0050.1.

Schlumberger, 1991. Log Interpretation Charts. Schlumberger Educational Services.

Stach A., 2009. Analiza struktury przestrzennej i czasoprzestrzennej maksymalnych opadów dobowych w Polsce $w$ latach 1956-1980 [Analysis of the spatial and spatial-temporal structure of maximum daily precipitation in Poland in the years 1956-1980]. Seria Geografia, 85, Wydawnictwo Naukowe Uniwersytetu im. Adama Mickiewicza, Poznań.

Thomsen L., 1986. Weak elastic anisotropy. Geophysics, 51, 10, 1954-1966. DOI: 10.1190/1.1442051.

Vanorio T., Mukerji T. \& Mavko G., 2008. Emerging methodologies to characterize the rock physics properties of organic-rich shales. The Leading Edge, 27, 780-787, DOI: 10.1190/1.2944163.

Vernik L. \& Nur A., 1992. Ultrasonic velocity and anisotropy of hydrocarbon source rocks. Geophysics, 57, 5, 727-735. DOI: 10.1190/1.1443286.

Vernik L. \& Liu X., 1997. Velocity anisotropy in shales: A petrophysical study. Geophysics, 62, 521-532.

Wang Z., 2002. Seismic anisotropy in sedimentary rocks, part 2, laboratory data. Geophysics, 67, 1423-1440. DOI: $10.1190 / 1.1512743$.

Wang Z., Wang H. \& Cates M.E., 2001. Effective elastic properties of solid clays. Geophysics, 66, 428-440.

Wenk H.R., Voltolini M., Mazurek M., Von Loon L.R. \& Vinsot A., 2008. Preferred orientation and anisotropy in shales: Callovo-Oxfordian shale France and Opalinus Clay Switzerland. Clays and Clay Minerals, 56, 285-306.

Tosaya C.A., 1982. Acoustic properties of clay-bearing rocks. Stanford University, Stanford [Ph.D. Thesis].

Zalewska J., Sikora G. \& Gąsior I., 2009. Laboratoryjne badania anizotropii sprężystych właściwości skał [Laboratory studies of anisotropy elastic properties of rocks]. Nafta-Gaz, 65, 9, 669-677.

Zhao L., Qin X., Han D.H., Geng J., Yang Z. \& Cao H., 2016. Rock-physics modeling for the elastic properties of organic shale at different maturity stages. Geophysics, 81, 5, D527-D541. DOI: 10.1190/GEO2015-0713.1.

Zhang F., Li X.-Y. \& Qian K., 2017. Estimation of anisotropy parameters for shale based on an improved rock physics model, part 1: theory. Journal of Geophysics and Engineering, 14, 143-158.

Zhu F., Gibson R.L. \& Estil R., 2001. A critical clay content model of sand-shale mixtures from log data in the Gulf of Thailand. [in:] SEG Technical Program Expanded Abstracts 2001, Society of Exploration Geophysicists, 1720-1723. 